\title{
A EVASÃO ESCOLAR NOS CURSOS TECNOLÓGICOS DO INSTITUTO FEDERAL DE EDUCAÇÃO, CIÊNCIA E TECNOLOGIA DE SÃO PAULO - IFSP
}

\author{
LA EVASIÓN ESCOLAR EN LOS CURSOS TECNOLÓGICOS DEL INSTITUTO \\ FEDERAL DE EDUCACIÓN, CIENCIA Y TECNOLOGÍA DE SÃO PAULO - IFSP
}

\author{
THE SCHOOL EVASION IN THE TECHNOLOGICAL COURSES OF THE FEDERAL \\ INSTITUTE OF EDUCATION, SCIENCE AND TECHNOLOGY OF SÃO PAULO - \\ IFSP
}

Solange Aparecida de Souza MONTEIRO ${ }^{1}$

Darwin IANUSKIEWTZ2

\begin{abstract}
RESUMO: O tema desta pesquisa, de cunho documental e qualitativa, é a evasão de alunos em cursos tecnológicos do ensino superior. A pesquisa se justifica ao verificar-se que ainda há um campo de conhecimentos pouco explorado sobre a evasão no ensino superior. O objetivo central foi identificar quais fatores causaram a evasão de alunos no Instituto Federal de São Paulo (IFSP), de um campus, no período de 2011 a 2017. Foram examinados documentos da instituição referentes a 746 alunos evadidos. Os resultados mostraram que, apesar das diferentes ações desenvolvidas pela instituição para conhecer os motivos e evitar a evasão, estas não foram consideradas satisfatórias pelos participantes da pesquisa. As causas apontadas pelos sujeitos entrevistados podem ser classificadas em: a) Escasso comprometimento com a evasão; b) Falhas organizacionais (limitações no sistema de gestão acadêmica e ausência de padronização para coleta e análise de dados sobre evasão); c) Falha no relacionamento entre setores.
\end{abstract}

PALAVRAS-CHAVE: Evasão escolar. Ensino cursos tecnológicos. IFSP. Gestão institucional.

RESUMEN: El tema de esta investigación, de cuño documental y cualitativo, es la evasión de alumnos en cursos tecnológicos de la enseñanza superior. La investigación se justifica al verificarse que todavía hay un campo de conocimientos poco explorado sobre la evasión en la enseñanza superior. El objetivo central fue identificar qué factores causaron la evasión de alumnos en el Instituto Federal de São Paulo (IFSP), de un campus, en el período de 2011 a 2017. Se examinaron documentos de la institución referentes a 746 alumnos evadidos. Los resultados mostraron que, a pesar de las diferentes acciones desarrolladas por la institución para conocer los motivos y evitar la evasión, éstas no fueron consideradas satisfactorias por los participantes de la investigación. Las causas señaladas por los sujetos entrevistados

\footnotetext{
${ }^{1}$ Instituto Federal de Ciência e Tecnologia de São Paulo (IFSP) Araraquara - SP - Brasil. Mestre em Processos de Ensino, Aprendizagem e Inovação. ORCID: 〈http://orcid.org/0000-0002-1640-0266>. E-mail: sol47monteiro@gmail.com

${ }^{2}$ Universidade de Araraquara (UNIARA), Araraquara - SP - Brasil. Doutor em Educação Escolar. ORCID: <https://orcid.org/0000-0002-5487-7401>. E-mail: darwin@profdarwin.com
}

Doxa: Rev. Bras. Psico. e Educ., Araraquara, v. 20, n. 2, p. 256-271, jul./dez., 2018. 
pueden clasificarse en: a) escasso compromiso con la evasión; b) Fallas organizativas (limitaciones en el sistema de gestión académica y ausencia de estandarización para la recolección y análisis de datos sobre evasión); c) Fallo en la relación entre sectores.

PALABRAS CLAVE: Evasión escolar. Enseñanza cursos tecnológicos. IFSP. Gestión institucional.

ABSTRACT: The subject of this research, documental and qualitative, is the evasion of students in technological courses of higher education. The research is justified by the fact that there is still a little explored field of knowledge about avoidance in higher education. The main objective of this study was to identify the factors that caused student dropouts at the Federal Institute of São Paulo (IFSP) in a campus from 2011 to 2017. Institutional documents were examined regarding 746 students who had been evaded. The results showed that, in spite of the different actions developed by the institution to know the reasons and avoidance, these were not considered satisfactory by the participants of the research. The causes pointed out by the subjects interviewed can be classified in: a) Scarce commitment to avoidance; $b$ ) Organizational failures (limitations in the academic management system and absence of standardization for collection and analysis of data on avoidance); c) Failure in the relationship between sectors.

KEYWORDS: School evasion. Teaching technological courses. IFSP. Institutional management.

\section{Introdução}

A evasão é considerada um fenômeno complexo e de amplo alcance, uma vez que abrange todos os níveis educacionais e traz implicações negativas para todos os envolvidos no processo de ensino aprendizagem. Tratando da educação superior pública, os estudos revelam a dimensão dessa problemática, apresentando índices preocupantes de abandono escolar no ensino superior e, por conseguinte, prejuízos econômicos e sociais aos sujeitos envolvidos. Os prejuízos provocados pela evasão escolar atingem os estudantes, a instituição, a sociedade e o governo. Assim como influencia os aspectos emocionais, psicológicos, humanos e financeiros, refletindo direta e indiretamente na sociedade, provocando a ausência de recursos humanos qualificados para o mercado de trabalho e contribuindo para a elevação dos índices de desemprego e expandindo as desigualdades sociais.

Foram analisados os dados dos estudantes evadidos que ingressaram na instituição no período compreendido entre 2008 e 2017.

Investigou-se o nível de informação que o aluno evadido tem acerca das políticas de acesso e permanência na instituição. 
Frequentemente, tem-se informações sobre colações de grau em que o número de concluintes é substancialmente menor do que o número de matriculados inicialmente no curso. De tal maneira que a evasão e o abandono escolar geram altos custos e ineficiência econômica.

As dificuldades enfrentadas pelo IFSP para identificar as variáveis associadas à intenção do estudante de evadir, muitas vezes, são reveladas tardiamente quando essa já é irreversível, após a saída do aluno ou quando esse já assumiu uma forte intenção de deixar o curso ou a instituição. A garantia do direito à Educação, conforme previsto na Constituição Federal Brasileira de 1988, está pautada nos direitos humanos, artigo 26 da Declaração Universal dos Direitos Humanos (1948), que são normas mínimas necessárias para uma vida digna. $\mathrm{O}$ direito à educação tem uma acepção mais ampla: trazer à baila a educação escolar. $\mathrm{O}$ processo educativo se inicia com o nascimento e ocorre ao longo da vida.

Estar cientes dos fatores relacionados à evasão, que ocorre em âmbito macro, as unidades acadêmicas, os departamentos, os núcleos de assistência e as pró-reitorias procuram trabalhar de forma a aproximar os professores e os alunos para que se construa uma política unificada dentro da instituição de ensino e para que se tenha um olhar abrangente do problema; isso possibilita visualizar que além da perda de recursos decorrentes da evasão escolar, tem-se os problemas inerentes às frustrações dos discentes, que muitas vezes tem seus sonhos interrompidos diante do abandono do curso. Sendo assim, não apenas docentes, mas também os profissionais da educação como reitor, pró-reitores, diretor, diretores adjuntos e coordenadores de cursos são fundamentais no combate ao fenômeno da evasão.

Freire $(2011$, p. 67) ajuda a compreender que o caminho para conter a evasão nos cursos superiores tecnológicos se faz caminhando e para tanto há de se considerar o que bem salienta o educador quando destaca que "a educação sozinha não transforma a sociedade, sem ela tampouco a sociedade muda".

A escola que se entende ser necessária, é aquela que se preocupa com a formação de seus docentes e por essa razão, compreende o educador e a educadora progressista, de acordo com Paulo Freire, como aquele que:

Não se permite a dúvida em torno do direito, de um lado, que os meninos e as meninas do povo têm de saber a mesma matemática, a mesma física, a mesma biologia que os meninos e as meninas das "zonas felizes" da cidade aprendem, mas, de outro, jamais aceita que o ensino de não importa qual conteúdo possa dar-se alheado da análise crítica de como funciona a sociedade. (FREIRE, 2000, p. 44) 
Almeja-se, que a escola, com seus educadores, possa trazer à tona as mudanças almejáveis para uma sociedade justa e igualitária. Isso não será possível se a escola não tiver nitidez de seu currículo, de sua proposta pedagógica, de seu sistema de avaliação no processo de ensino e de aprendizagem, com compromisso, competência de agir e refletir sobre a realidade. De acordo com Freire:

Se o meu compromisso é realmente com o homem concreto, com a causa de sua humanização, de sua libertação, não posso por isso mesmo prescindir da ciência, nem da tecnologia, com as quais me vou instrumentando para melhor lutar por esta causa. (2007, p. 22)

Constituir na escola, a partir de seu processo histórico, a reflexão crítica sobre a realidade, permitindo o cumprimento e a inserção de todos. Sobre isto, Freire (2007, p. 25), afirma a necessidade de o educador assumir o "compromisso com os destinos do país. Compromisso com seu povo. Com o homem concreto. Compromisso com o ser mais deste homem".

Paulo Freire expressa que a escola deve ser um lugar de trabalho, de ensino, de aprendizagem. Um lugar em que a convivência permita estar ininterruptamente se superando, porque a escola é o espaço privilegiado para pensar. Ele que sempre acreditou na capacidade criadora dos homens e mulheres, e pensando assim é que apresenta a escola como instância da sociedade.

Nesse sentido, o homem passa a reconhecer suas tarefas fundamentais, o que só é possível quando deixa de ser dominado pelos mitos, onde a razão passa a predominar sobre a emoção. Pois, quanto mais o homem for capaz de refletir sua realidade, maiores condições terão de agir sobre ela, comprometendo-se assim em mudá-la, pelo fato de sentir-se inserido, partícipe, produtivo nela. Assim, o trabalho educativo será expressão da consciência crítica, quando os homens que o fazem, manifestam a capacidade de diálogo orientada para a práxis.

A educação crítica é orientada para a tomada de decisões e o exercício da prática de uma responsabilidade social e política. Modificando-se assim, a própria relação entre professor e aluno, a qual é marcada pelo pressuposto básico que Paulo Freire estabelece para esta relação, a saber, a prática do diálogo enquanto dimensão essencial no trabalho de compreensão da realidade a partir das experiências do sujeito lecionador, assim como do sujeito lecionado. Portanto, a comunicação entre educador e educando, na partilha de suas experiências pelo diálogo, abre caminhos para uma participação responsável. O diálogo implica reconhecimento do outro, através do respeito a sua dignidade, o que só é possível 
entre pessoas, e o qual se fundamenta na democracia. Paulo Freire traz para a escola o princípio da relação professor-aluno.

No esforço para a compreensão do fenômeno da evasão escolar e para que a permanência do aluno fosse garantida, uma série de ações começaram a serem elaboradas, refletidas, reestruturadas e firmadas também pela Pró Reitoria de Ensino do IFSP. Entretanto, estas ações estratégicas recaem sobre a necessidade permanente de reflexão, que trazem à tona a figura dos gestores como sujeitos coparticipantes deste processo, quer seja pela natural incumbência do cargo, quer pela responsabilidade que lhe foi atribuída:

As instituições devem estar comprometidas com o bem-estar dos estudantes acima de quaisquer outras necessidades institucionais. As instituições devem estar comprometidas em primeiro lugar com a educação de todos e não somente de alguns. As instituições devem estar comprometidas com o desenvolvimento de comunidades sociais e educacionais capazes de dar suporte aos alunos e nas quais todos possam ser integrados como membros integrais (TINTO, 1987 apud LIMA JR., 2013, p. 10).

No Brasil, há poucos estudos sistemáticos e dados nacionais sobre evasão. Por esse motivo, o Instituto Lobo para o Desenvolvimento da Educação, da Ciência e da Tecnologia decidiu realizar um trabalho de coleta e organização dos dados sobre a evasão brasileira, acrescentando dados internacionais para comparação, no intuito de contribuir com a comunidade acadêmica brasileira para o aprofundamento dos estudos sobre tema tão relevante. Atualmente os idealizadores moram em Boston e trabalham junto ao IEC International Entrepreneurship Center - para ampliar e desenvolver a atuação na área de Educação, Empreendedorismo e Inovação, em especial com Instituições de Ensino Superior (IES) brasileiras. ${ }^{3}$

Os cursos superiores de graduação ofertados pelo IFSP têm variado ao longo de sua história, tanto em número quanto em tipo de ensino. Isso se deve ao fato da evolução de sua estrutura regimental, bem como estrutura física e ampliação do número de escolas.

Lahire e Bourdieu concordam que os indivíduos sejam portadores de disposições práticas incorporadas de suas experiências sociais e que essas disposições orientem as ações futuras desses sujeitos. Contudo, Lahire (apud LIMA JR., 2013, p. 7) argumenta que a experiência social à escala individual é mais heterogênea que qualquer esquema de classes sociais poderia prever e, igualmente, o conjunto das disposições práticas incorporadas pelos indivíduos propriamente ditos, só forçosamente poderia configurar um sistema de disposições que mantenha correspondência com a origem social desses indivíduos.

${ }^{3}$ Disponível em: <http://institutolobo.org.br/paginas/home.php>. Acesso em: 13 dez. 2017.

Doxa: Rev. Bras. Psico. e Educ., Araraquara, v. 20, n. 2, p. 256-271, jul./dez., 2018. 
A presente pesquisa problematiza as decisões de evasão escolar, abandono e desistência em permanecer nos cursos tecnológicos em um dos campi do IFSP, interpelando os docentes, estudantes, servidores técnicos administrativos e gestores, quanto à busca da permanência e êxito dos estudantes. Há a necessidade de pesquisar a evasão como um problema de gestão institucional e de comando do IFSP para o estabelecimento de políticas que conduzam as ações de enfrentamento à evasão. Deve-se também verificar se existem ações e como elas estão sendo desenvolvidas pela instituição para conhecer os motivos da evasão de seus estudantes.

A pesquisa sobre a evasão, e no caso específico sobre a evasão nos cursos tecnológicos do IFSP - do campus pesquisado apresenta um desafio: encontrar uma abordagem teórica que facilite a articulação entre os fatores causadores da evasão escolar nesses cursos. Desse modo, sem pretensão de findar o tema e destituída de qualquer intenção de restrição teórica, tenta-se fazer as aproximações possíveis entre os fundamentos sociológicos e as políticas para estudar a questão.

\section{Panorama histórico da educação profissional federal e a evasão escolar no Brasil}

Desde o início da colonização até mais ou menos o final da década de 1970, quando se consolidou o processo de democratização no Brasil, a educação foi para poucos, excluindo-se a maioria, a qual nem sequer ingressava na escola, conforme cita Saviani (1999, p. 3): "De acordo com estimativas relativas a 1970, cerca de 50\% dos alunos das escolas primárias desertavam em condições de semi-analfabetismo ou de analfabetismo potencial na maioria dos países da América Latina (TEDESCO, 1981, p. 67). Isto sem levar em conta o contingente de crianças em idade escolar que sequer têm acesso à escola e que, portanto, já se encontram a priori marginalizadas dela."

O acesso ao Ensino Superior no Brasil é uma realidade ainda distante para grande parcela da população brasileira, embora o governo e as universidades tenham investido na mudança desse cenário oportunizando outras formas de acesso, além do tradicional vestibular, e com políticas públicas para manter o aluno da universidade.

No Brasil, ao mesmo tempo em que há grande concorrência por vagas em universidades, há uma considerável diferença entre o número de alunos que ingressam no ensino superior e aqueles que conseguem se diplomar. Esta discrepância se deve aos elevados índices de abandono dos estudos por parte dos universitários. De acordo com o Mapa do Ensino Superior, a taxa de abandono nas instituições públicas em 2014 chegou a 18,3\% nos 
cursos presenciais e a 26,8\% nas modalidades à distância (EAD). No caso das instituições particulares, os índices de evasão chegam a 27,9\% nas graduações presenciais e $32,5 \%$ em cursos EAD (SEMESP, 2016). Com isso, políticas que miram na democratização do ensino superior, como o sistema de cotas e a criação de novas universidades, podem não se mostrar eficientes frente aos altos índices de evasão do país.

No Brasil, a educação profissional passou a ter relevância nos últimos anos nos projetos institucionais e, principalmente, governamentais, o Brasil investiu em 2012, aproximadamente $5,2 \%$ do PIB com educação - superior aos 4,8\% da média dos países da OCDE - sem, no entanto, reduzir os altos índices de evasão e uma das maiores taxas de repetência escolar do mundo, superando apenas alguns países africanos de baixa renda. Um desafio aos governantes, consequentemente, advém de que a educação de qualidade não depende apenas do aumento dos gastos (INEP/2012). Tanto a evasão quanto o abandono escolar, geram altos custos e ineficiência econômica representando um obstáculo para a melhoria dos indicadores educacionais que se refletem diretamente no crescimento econômico, mercado de trabalho e, portanto, no bom desempenho de toda a sociedade. Assim, é imperiosa a compreensão das causas que provocam a evasão para que se encontrem alternativas para combatê-la. A evasão escolar do ensino superior comprova-se como fenômeno complexo, de natureza pessoal, institucional, social e econômica.

Quadro 1 - Evasão nos cursos tecnológicos do campus Pesquisado do IFSP, de acordo com os motivos de cancelamento de matrícula (Tecnologia em Análise e Desenvolvimento de Sistemas (ADS), Tecnologia em Manutenção de Aeronaves, Tecnologia em Processos Gerenciais).

\begin{tabular}{|c|c|c|c|}
\hline Motivo do Cancelamento & ADS & TMA & TPG \\
\hline Reingresso & 5 & 1 & 1 \\
\hline Desistência & 4 & 1 & 0 \\
\hline Mudança de curso & 23 & 12 & 9 \\
\hline Horário do curso & 0 & 0 & 2 \\
\hline Impossibilidade de tempo & 6 & 0 & 0 \\
\hline Rematricula com outro prontuário & 5 & 0 & 0 \\
\hline Faltas excedidas em todas as disciplinas & 3 & 0 & 0 \\
\hline Interesse em outra carreira profissional & 3 & 0 & 0 \\
\hline Fazer curso pré-vestibular & 1 & 0 & 0 \\
\hline Não se identificou com o curso & 14 & 3 & 0 \\
\hline Demora das dispensas de disciplinas & 0 & 1 & 0 \\
\hline Não adaptação ao período noturno & 1 & 0 & 0 \\
\hline Dependências de disciplinas & 1 & 0 & 0 \\
\hline Impossibilidade de cumprir as obrigações & 1 & 0 & \\
\hline
\end{tabular}

Doxa: Rev. Bras. Psico. e Educ., Araraquara, v. 20, n. 2, p. 256-271, jul./dez., 2018. 


\begin{tabular}{|c|c|c|c|}
\hline Cancelado ex-officio & 294 & 107 & 03 \\
\hline Trabalho & 10 & 1 & 0 \\
\hline Matrícula em outra instituição & 14 & 9 & 3 \\
\hline Ingresso em outra IES & 42 & 0 & 5 \\
\hline Pleitear bolsa do PROUNI & 1 & 0 & 0 \\
\hline Moradia & 2 & 2 & 1 \\
\hline Mudança de cidade & 4 & 0 & 0 \\
\hline Transferência & 5 & 0 & 0 \\
\hline Cancelado a pedido & 1 & 1 & 0 \\
\hline Familiar & 1 & 0 & 0 \\
\hline Financeiro & 3 & 0 & 1 \\
\hline Motivos de saúde & 2 & 1 & 1 \\
\hline Motivos pessoais & 4 & 0 & 1 \\
\hline Viagem fora do país & 0 & 7 & 0 \\
\hline Não apresentou motivos & 3 & 158 & \\
\hline Total & 453 & & \\
\hline
\end{tabular}

Fonte: Elaborado pela pesquisadora (2018)

\section{A construção da identidade e a evasão escolar}

A identidade não é algo que pode ser adquirido de forma definitiva e externa. Ela é escorregadiça e constitui-se num processo de construção, e reconstrução permanente, pois cada lugar e cada tempo demandam redefinições. Trata-se, de um processo de construção do sujeito historicamente posicionado. Ela ocorre, portanto em um determinado contexto social e cultural em constante transformação que se dá na interseção entre a construção biográfica e a histórica das práticas sociais e educacionais, abrangendo, dessa forma, a simbologia das mais diferentes concepções.

Pode-se estabelecer como identidade um conjunto de particularidades pelas quais alguém pode ser reconhecido na perspectiva sociológica, identidade pode ser definida como: características especificas do caráter de um grupo que se relaciona com o que eles são e como que tem sentido para eles. Qualquer das principais fontes de identidade é um marcador importante da identidade individual, é dar um nome, um ponto de vista da identidade do grupo (GIDDENS, 2004, p. 17).

A identidade possui uma dimensão individual, isto é, concepções e representações que construímos sobre nós mesmos, e uma dimensão coletiva, os papeis sociais que são desempenhados em cada grupo do qual se pertence (familiar, profissional, escolar, religioso etc). Para a construção da identidade, portanto, concorrem dois processos distintos, a saber, um processo autobiográfico (a identidade do eu) e um processo relacional (a identidade para o outro) (DUBAR, 1991, p. 119). 
As decisões "citadas" como definitivas nem sempre são, por fatores que dependem ou não dos entrevistados. Isso talvez seja fruto da modernidade líquida como esclarece. Em estágio mais recente, a 'modernidade líquida' expressa por esse filósofo revela que o mundo é caracterizado pela mutação constante, pela fluidez de estruturas, determinando flexibilidade estrutural, organizacional e relacional.

Quando se trata de sujeitos sociais que compartilham territórios, tempos e representações sociais na escola e sobre ela, não se pode deixar de considerar o contexto mais amplo em que cada um dos sujeitos está posto intimamente em suas expectativas e percepções.

As identidades flutuam no ar, algumas de nossa própria escolha, mas outras infladas e lançadas pelas pessoas em nossa volta, e é preciso estar em alerta constante para defender as primeiras em relação às últimas (BAUMAN, 2005, p. 19).

Dentro desse círculo de pertencimento, identidade, poucos de nós, ou quase ninguém, está exposto a apenas uma comunidade de ideias e princípios, a pessoa está sempre se construindo, de acordo com as vivências e experiências do meio em que se está inserido.

Em sua trajetória pessoal, o aluno vive em constantes mudanças. O convívio com as diferenças é importante para o reconhecimento e compreensão de sua própria identidade. $\mathrm{O}$ aluno de uma instituição de ensino superior carrega uma identidade pessoal formada conforme moldes culturais em que estava inserido antes de adentrar a instituição.

Tornamo-nos conscientes de que pertencimento e a identidade não tem a solidez de uma rocha não são garantidos e de que as decisões que o próprio indivíduo toma os caminhos que percorre, a maneira como age e são fatores cruciais tanto para o "pertencimento" ideia de ter uma identidade não ocorrer as pessoas enquanto o "pertencimento" continuar sendo seu destino, uma condição sem alternativa. Só começarão a ter essa na forma de uma tarefa a ser realizada vezes e vezes sem conta, e não de uma só tacada (BAUMAN, 2005, p. 17-18).

Em sua trajetória pessoal, o estudante vive em constantes mudanças, o convívio com as diferenças é importante para o reconhecimento e compreensão de sua própria identidade. $\mathrm{O}$ estudante de uma instituição de ensino superior carrega uma identidade pessoal formada conforme moldes culturais em que estava inserido antes de adentrar a instituição.

A necessidade de se tornar membro dessa nova comunidade social (a instituição de ensino) exige dele grande capacidade de adaptação. O estudante deverá internalizar e se adequar às normas, costumes, símbolos e diferenças presentes no novo ambiente. 
Para entender o processo de evasão, faz necessário identificar como a auto percepção da identidade pelo aluno influencia sua trajetória acadêmica. A importância da construção da identidade dentro do contexto universitário para interação aluno-comunidade escolar. A não construção da identidade nesse contexto pode levar o aluno à evasão.

Diminuir o problema da evasão é fundamental, acolher o aluno com um olhar na sua identidade atual. Deve-se apoiar a formação de uma identidade que o faça sentir-se parte integrante da comunidade escolar. A forma como a instituição de ensino se compromete com esse acolhimento é determinante.

$\mathrm{Na}$ vida acadêmica, o aluno atravessa fases no processo de aprendizagem, definição de sua identidade e pertencimento à comunidade da instituição de ensino. Ele, com uma concepção de si formada por suas interações com o mundo doméstico e social, apresenta expectativa em relação ao curso pelo qual optou, à universidade, aos professores, aos colegas de curso e traz consigo intenções, objetivos e compromissos.

Cabe à instituição de ensino superior adotar as medidas concretas que auxiliam na reconstrução da identidade do aluno, diminuindo assim a evasão. A aproximação entre a identidade da instituição e a identidade do aluno exige que o ensino seja crítico, orientado à realidade e às necessidades sociais. Exige a constante atualização do projeto político pedagógico e o acompanhamento individualizado do estudante, uma vez que a evasão tem causas heterogêneas. Impõe, por fim, o comprometimento do corpo docente com a inclusão dos alunos nesse novo ambiente portando-se como investigadores, pesquisadores, facilitadores, do conhecimento, de modo à efetividade em transmiti-lo, em vez de somente expô-lo.

Dechamps e Moliner (2009) nos orientam para a necessidade de levar em conta na formação da identidade social, a avaliação que o aluno tem de si mesmo, do seu grupo de pertença, do que pensa que outros têm dele, de suas explicações para seu sucesso e seu fracasso e pela forma que encaram o futuro.

Cada organização demarca uma cultura organizacional única, gerada e sustentada pelos mais distintos elementos e formas, isso constitui que a cultura de uma organização sofre influência de seus fundadores, líderes de seu processo histórico.

\section{A evasão escolar: um problema de gestão institucional}


Concluiu-se que a gestão institucional e se operacionalidade destes problemas recorrentes como a evasão escolar não fosse conduzida como questão secundária do cotidiano institucional, deixando de identificar como efetivo desvio da função social da Instituição.

Nesse cenário a evasão escolar ainda não foi encaminhada pela gestão institucional como pauta essencial do ambiente institucional. Em um espaço público de pouco debate, não se constituiu uma estrutura democrática suficiente para constituir um planejamento integrado para dar conta de identificá-la como problema de gestão institucional, estabelecer prioridades, mas também fosse chamada a responsabilização dos desvios da função social do IFSP causados por esse fenômeno.

A obra Vigiar e Punir apresenta um estudo sobre a constituição do poder disciplinar na sociedade Moderna e identifica a forma como instituições como o hospital, a escola e a prisão transformam-se em instituições disciplinares por excelência a partir meados do século XVII e XVIII. Rompendo com a concepção tradicional de poder enquanto uma propriedade de determinado grupo social, Foucault o entende a partir de uma perspectiva relacional, microfísica, um incessante exercício de dominação de um grupo ou indivíduo sobre outro.

Toda forma de poder é produtora de saber que, por sua ver, retorna sobre o agente como potencializadora de estratégias e dispositivos de dominação. Na Modernidade, a disciplinarização se produz por meio de um exercício de economia do poder, tornando-o microfísico e invisível.

Para que isso aconteça, os dispositivos de exame, normalização e controle se consolidam a partir da produção de determinados saberes sobre o indivíduo. É preciso conhecer os corpos em suas minúcias, para que se possa dominá-lo, para promover sua utilidade. A sociedade disciplinar exige também o exame que se constitui como um dos instrumentos fundamentais para o exercício do poder, pois é um olhar normalizador, uma vigilância que qualifica, classifica, castiga, diferencia e sanciona (FOUCAULT, 1987).

Os documentos institucionais comprovam a complexidade deste enfrentamento para a gestão. Se por um lado se estabeleceu um conjunto de documentos que previam a atuação em torno dos problemas de evasão escolar, por outro, há o distanciamento entre o que se definiu como prioridade nesses documentos e o que, de fato, foi encaminhado a partir dessas normas.

Comprovou-se a partir do estudo dos documentos institucionais que embora o MEC pactuou metas para serem cumpridas sobre a evasão escolar no IFSP, na prática a gestão institucional, essas demandas não apareceram no cotidiano de nenhum dos dois órgãos.

Os baixos índices de permanência de alunos na Instituição como um todo e no campus onde a pesquisa foi realizada, confirma a necessidade de consolidação da política de gestão 
democrática, onde estudos técnicos devam balizem o debate coletivo sobre os destinos que devem ser traçados pelos campi para mitigar esse fenômeno. Há que construir uma maior responsabilização de todos os envolvidos com a vida acadêmica e romper com um ciclo de desperdício de recursos públicos que tanto prejudica a melhoria da educação brasileira.

Entretanto, a alternativa para a construção de resistências e enfrentamentos a esse processo está também na consolidação de um ambiente efetivamente democrático, que poderá ocorrer por meio da organização dos servidores, a consolidação das instâncias de representação sindical, a organização estudantil forte e atuante, a sensibilização e responsabilização dos docentes e técnico-administrativos para atuação mais efetiva no cotidiano da Instituição.

A Instituição necessita criar mecanismos para esse debate e unificação que vão além das instâncias já estabelecidas, um diretor-geral pode conduzir o planejamento do campus em um espaço de diálogo institucional, a partir de debates que resultem em acumulação democrática. Não é um empenho institucional e dentro de uma institucionalidade, mas um espaço de interlocução horizontal, que construa efetivamente um plano de proposições e ações e que persiga um projeto maior para o IFSP. Balizados no PDI, esses espaços devem ser perenizados para a consolidação desse ambiente democrático institucional.

O IFSP é uma Instituição em que a gestão institucional poderá ser superada pelo aprofundamento das relações democráticas criadas em uma correlação de forças que sejam capazes de realizar os debates e os diálogos necessários. As transformações ocorrerão por dentro, no processo democrático da participação de toda a comunidade acadêmica. Reafirmando sua função social e se voltando para o conjunto dos seus servidores/estudantes e externamente para sociedade, incorporando a população como elemento de reflexão e diálogo, consolidando, enfim, a formação integral dos estudantes.

\section{Considerações finais}

Concluiu-se na pesquisa que o aluno prescinde de sentir o pertencimento na instituição escolar, ficou evidenciado nas entrevistas, o susto que o aluno leva ao ingressar no IFSP. Em outras palavras, o processo de integração do aluno ao novo ambiente, que lhe é desconhecido, é bastante complexo. Do ponto de vista do estudante ingressante isso parece ser importante, mas as queixas em relação à falta de informações sobre o IFSP e o curso são elementos importantes para uma profunda reflexão sobre o papel da instituição na vida dos alunos. 
Ressalta-se, que esse fenômeno da evasão, não pressupõem que o IFSP não apresente deficiências ou fraquezas que dificultam uma documentação mais contundente dos limites e barreiras institucionais. Verdadeiramente, são destacadas dificuldades distintas, como falta de atualização das práticas pedagógicas, categoria das carreiras, algumas limitações para a inserção de grupos múltiplos em distintos espaços do campus, além da perda de significado e finalidade das conjecturas acadêmicas sobrevindas de um espectro distorcido de produção do conhecimento. No entanto, há um desejo de negociação para o espaço de intervenção do sujeito sobre a conjuntura ou meio que também integra. Portanto, o campus e em caráter mais amplo o IFSP não é integralmente fechado e rígido ao ponto de não se moldar às diversas variáveis e ajustes à sua missão.

Em relação a isso, ressalta-se ocorrências de alunos com condições bastante antagônicas que destacaram no curso e estão bem situados no mercado de trabalho atual, sem tanto apoio, ou vivenciado as mesmas dificuldades institucionais que os demais estudantes analisados. Desse modo, constata-se, muito comumente, que eram enunciadas possibilidades para as quais se direcionaram diferentes indivíduos, e cada um se deslocou para um ponto que lhe pareceu mais conveniente no instante de ação.

A pesquisa apontou como caminho para conter a evasão, no âmbito do campus, o fortalecimento dos mecanismos já existentes, como o Projeto Político Pedagógico - PPP, a flexibilidade, a modernização dos cursos, a criação da mostra de profissões e a maior integração professor-instituição.

Constata-se que tais encaminhamentos ressoaram em desdobramentos mais ou menos exitosos segundo o desenlace alcançado no curso. Assim, confere-se que todos os estudantes que concluem observem elevação do meio social de origem, percebam resultados não somente do ponto do aspecto material, mas de obtenção do saber e durabilidade pessoal, apoderar-se com disciplina e atenção ao curso, em relação aos problemas do campus do IFSP.

Concluiu-se que sensação de abandono induz a sentimento de perda, de fracasso. E tais sensações, nos remetem a um comprometimento maior da instituição nos projetos pedagógicos em curso, reações que considerem ações que otimizem o diálogo, a conversa e podem reverter a desistência do aluno na instituição. Ações mais vigorosas que promovam atuação da coordenadoria socio pedagógica, propositiva e não apenas reativa diante de um pedido de socorro eventual por parte de docentes ou coordenadores de curso, ou de um alerta de um professor. Ações dessa natureza parecem ser cada vez mais necessárias e urgentes nesse novo cenário estudantil do campus pesquisado. 
Os baixos índices de permanência de alunos na Instituição como um todo e no campus pesquisado em particular, confirma a necessidade de uma política de gestão democrática, onde estudos técnicos devam balizar um debate coletivo sobre os destinos que devem ser traçados pelos campi para mitigar esse fenômeno. Há que construir uma maior responsabilização de todos os envolvidos com a vida acadêmica e romper com um ciclo de desperdício de recursos públicos que tanto prejudica a melhoria da educação brasileira.

Outro aspecto que a pesquisa permitiu aclarar relacionou-se ao fato de os fatores sociais não serem os estruturantes a ponto de paralisar a disposição que alguns estudantes demonstraram em organizar e gerir suas trajetórias de vida. Diante disso, a pesquisa pode apontar direções para as medidas de políticas públicas quando evidencia esse aspecto dos resultados obtidos.

Enfim, tendo em vista o fato de as preocupações com a evasão e o abandono dos cursos apontarem índices altos, aproximando-se de 30\%, demandando prudência para tais indicadores, pode-se assegurar que: qualquer grau que procure confrontar-se os índices da evasão deve ser tomado em concordância com as especificidades dos elementos apontadas. Resguarda-se, assim, em face daquilo que se estima como contribuição desta pesquisa, que as medidas tomadas, em geral, com vistas a diminuir os índices da evasão, resultariam em esforço ineficaz se não forem devidamente consideradas as necessidades específicas dos grupos distinguidos.

Para Freire (2003, p. 52), “o papel do professor e da professora é ajudar o aluno e a aluna a descobrirem que dentro das dificuldades há um momento de prazer, de alegria". Para tanto, torna-se prioritário a prática do diálogo em que ambos, educador e educando, através da realização de seus objetivos chegam ao acesso do saber historicamente elaborado pelo exercício cultural da humanidade. Ainda de acordo com Freire (2003, p. 177), “O educador ou educadora como um intelectual tem que intervir. Não pode ser um mero facilitador", o que traduz a permanência na escola, o sucesso, o acesso concreto ao ensino e aprendizagem.

Na Pedagogia Histórico-Crítica defendida por Saviani (1999), professor e aluno são sujeitos ativos, situados numa realidade e o professor o mediador do processo pedagógico, interferindo e criando as condições para que este se aproprie do conhecimento. $\mathrm{O}$ docente deve conhecer o contexto em que seu aluno está inserido e ser consciente que a ação de ensinar é política e por isso, tem comprometimento político com a socialização, tanto do conhecimento científico, como cultural.

Os resultados referentes à evasão, mostram que esse é um grande problema a ser enfrentado pelo IFSP - no campus pesquisado. Esse resultado contribui para afirmar, através 
de dados efetivos, a constatação publicada no Plano de Desenvolvimento Institucional (PDI) 2014 - 2018, de que "a evasão continua a ser um dos maiores desafios para a gestão do IFSP” (IFSP, 2014, p. 141). Em adição, a quantidade de alunos concluintes mostrou índices bem baixos, se comparar a quantidade de ingressos com os que de fato se formam. Essa realidade tem consequências também financeiras, uma vez que um dos critérios considerados na elaboração das propostas orçamentárias é "o número de matrículas e a quantidade de alunos ingressantes e concluintes em todos os níveis e modalidades de ensino em cada período" (BRASIL, 2010).

\section{REFERÊNCIAS}

BAUMAN, Zygmunt. Identidade. Tradução de Carlos Alberto Medeiros. Rio de Janeiro: Jorge Zahar Editor, 2005.

BRASIL. Decreto no 7.234 de 19 de julho de 2010. Programa Nacional de Assistência Estudantil: PNAES, 2010. Disponível em: http://www.planalto.gov.br/ccivil_03/_Ato20072010/2010/Decreto/D7234.htm. Acesso em: 15 out. 2016.

DESCHAMPS, Jean Claude.; MOLINER, Pascal. A identidade em psicologia social: dos processos identitários às representações sociais. Tradução de Lúcia M. Endlich Orth. Petrópolis: Vozes, 2009.

DUBAR, Claude. A socialização: construção das identidades sociais e profissionais. Tradução. Anette Pierrette R. Botelho e Estela Pinto R. Lamas. Portugal: Porto Editora, 1997.

FOUCAULT, Michel. Vigiar e punir. Trad. Raquel Ramalhete. 27. ed. Petrópolis: Vozes, 1987.

FREIRE, Paulo. Pedagogia da indignação: cartas pedagógicas e outros escritos. São Paulo: UNESP, 2000.

FREIRE, Paulo. Pedagogia da autonomia: saberes necessários à prática educativa. 28. ed. São Paulo: Paz e Terra, 2003. 148 p.

FREIRE, Paulo. Educação como prática da liberdade. 30 ed. São Paulo: Paz e Terra, 2007. FREIRE, Paulo. Educação como prática de liberdade. São Paulo, 2011.

GIDDENS, Anthony. Sociologia. 4 ed. Lisboa: Fundação Calouste Gulbenkian, 2004.

IFSP. Plano de Desenvolvimento Institucional. (PDI) 2014-2018. Portaria $n^{\circ} 3.528$ de 2015. Cria a Comissão Interna de Acompanhamento das Ações de Permanência e Êxito dos Estudantes - CIPEE. Documento Interno. Disponível em: www.ifsp.edu.br/index.php/documentos-institucionais/pdi.html. Acesso em: 15 mar. 2017. 
LAHIRE, Bernard. La Culture des individus: Dissonances culturelles et distinction de soi, Paris, La Découverte, Laboratoire des sciences sociales, 2004.

LIMA JUNIOR, Paulo R. Menezes. Evasão do ensino superior de física segundo a tradição disposicionalista em sociologia da educação. 2013. 329 p. Tese (Doutorado em Ensino de Física) - Instituto de Física, Universidade Federal do Rio Grande do Sul, Porto Alegre, 2013.

SAVIANI, Dermeval. Escola e democracia. 6 ed. São Paulo: Cortez Editora/Autores Associados, 1980.

SAVIANI, Demerval. Pedagogia histórico-crítica: primeiras aproximações. $8^{\mathrm{a}}$ ed. Campinas: Autores Associados, 2002.

SEMESP. Disponível em: http://www.semesp.org.br/tag/evasao/. Acesso em: 16 nov. 2016.

TEDESCO, Juan Carlos. Elementos para un diagnóstico dele sistema educativo tradicional en América Latina. In: UNESCO/CEPAL/PNUD. El cambio educativo: situación y condiciones. Informes Finales 2, 1981.

TINTO, Vicent. Dropout from Higher Education: a theoretical synthesis of recent research. Review of Educational Research, v. 45, n. 1, p. 89-125, 1975.

\section{Como referenciar este artigo}

MONTEIRO, S. A. de S.; IANUSKIEWTZ, D. A evasão escolar nos cursos tecnológicos do instituto federal de educação, ciência e tecnologia de são paulo - IFSP. Doxa: Rev. Bras. Psico. e Educ., Araraquara, v. 20, n. 2, p. 256-271, jul./dez., 2018. e-ISSN: 2594-8385. DOI: 10.30715/doxa.v20i2.12024

Submetido em: 10/08/2018

Aprovado em: 23/10/2018 